\title{
CRACK PROPAGATION ANALYSES WITH CTOA AND COHESIVE MODEL: COMPARISON AND EXPERIMENTAL VALIDATION
}

\author{
Scheider, I., Schödel, M. and Schönfeld, W. \\ GKSS Research Centre Geesthacht \\ Max-Planck-Str. 1; D - 21502 Geesthacht; Germany \\ ingo.scheider@gkss.de
}

\begin{abstract}
Two numerical crack propagation models, namely the cohesive model and the CTOA model, are compared regarding their ability to predict the crack propagation behaviour of fracture specimens made of thin walled Aluminium sheets, which can be simulated using plane stress assumption. The experimental database is presented and it is shown, how the various quantities are measured by different techniques (optically and with various clip gauges). It is explained how the respective parameters for the numerical models are determined by use of a selected set of fracture specimens. Other types of specimens are then used to validate the simulations with these parameters. In order to investigate the behaviour of the models under different constraint conditions and the transferability of their parameters, $\mathrm{C}(\mathrm{T})$ specimens are used for parameter evaluation and $\mathrm{M}(\mathrm{T})$ specimens for validation. It is shown that for all types of specimens, a single set of parameters can be used for both models.
\end{abstract}

\section{Introduction}

Thin aluminium sheets have a wide range of applications, especially in modern transportation industries. Since the safety of passengers and environment requires a safe design of machines and structures, but the production cost, on the other hand, requires economical usage of material, the dimensioning of the structures must be as exact as possible. A special issue in the design process is the so-called damage tolerant design, that means a structure that is partly damaged must in no case fail in an unstable manner. Even though the analytical methods, which have been developed for easier assessment of simple structures, are now able to predict failure of more complex ones (see e.g. [1, 2]), numerical simulations can still be very helpful here, since very complex three-dimensional structures with cracks can hardly be assessed analytically. Within the last three decades, several models for the analysis of crack propagation have been developed, since the determination of the crack initiation, e.g. by $K$ or $J$ concepts, does not give enough information about life of a structure in service. Two models which have attracted special attention are the CTOA (crack tip opening angle) and the cohesive model.

The CTOA, which has been introduced particularly for describing crack extension in metal sheets $[3,4]$, is used as the characteristic parameter in crack propagation analyses where the crack extension itself is realised by a node release technique. The advantage of this model is that it has only a single parameter, the critical CTOA $\psi_{\mathrm{c}}$, to model the fracture process, which can be determined by experiments [5]. A drawback is that only initially flawed structures can be analysed with this model. The underlying assumption for the application of the model is that after initiation of crack extension no further crack-tip blunting occurs, and the near crack 
tip deformation field is characterised by a specific $\psi$, which can be used as a criterion of crack extension [6],

$$
\psi=\psi_{\mathrm{R}}(\Delta a) \text {. }
$$

The CTOA criterion is closely related to the crack driving force parameter, the CTOD (crack tip opening displacement), $\delta$. A unique definition of a CTOD value for laboratory specimens as well as components, the $\delta_{5}$, has been proposed in [7]. Within a defined application range, CTOA is related to a $\delta_{5}$ R-curve by

$$
\psi=\tan ^{-1}\left(\frac{d \delta_{5}}{d a}\right) \approx \frac{d \delta_{5}}{d a} .
$$

Cohesive models $[8,9]$ allow for separation of interfaces between continuum elements, if some critical value of a separation is reached locally, whereas the material outside deforms according to elasto-plastic constitutive equations without any damage. The so-called process zone is a material volume, and material separation and fracture are controlled by a cohesive law, which has the general form $\sigma=f(\delta)$, where $\delta=[\mathbf{u}]$ is the corresponding value of the displacement jump between adjacent continuum elements. In general, $\mathbf{u}$ is a vector quantity, but in mode I fracture, the normal component, $\delta_{\mathrm{n}}$, is sufficient for the crack propagation analysis (applications with shear fracture and mixed mode are for example described in [10]). Cohesive elements can be used in 2D and 3D models. Only a few applications exist for crack extension in metal sheets, see e.g. [11].

Various functions exist for the cohesive law [8-10], which have in common, that they contain two characteristic parameters (per fracture mode), a cohesive strength, $\sigma_{0}$, and a critical separation, $\delta_{\mathrm{c}}$. The cohesive law proposed by Scheider [12],

$$
\sigma=\sigma_{\mathrm{c}}\left\{\begin{array}{cc}
2\left(\frac{\delta}{\delta_{1}}\right)-\left(\frac{\delta}{\delta_{1}}\right)^{3} & \text { for } \delta \leq \delta_{1} \\
1 & \text { for } \delta_{1} \leq \delta \leq \delta_{2} \\
2\left(\frac{\delta-\delta_{2}}{\delta_{\mathrm{c}}-\delta_{2}}\right)^{3}-3\left(\frac{\delta-\delta_{2}}{\delta_{\mathrm{c}}-\delta_{2}}\right)^{2}+1 & \text { for } \delta_{2} \leq \delta \leq \delta_{\mathrm{c}}
\end{array}\right.
$$

has been implemented as a user-defined element (UEL) in the FE code ABAQUS [13]. The values for the shape parameters $\delta_{1}$ and $\delta_{2}$ are $\frac{\delta_{1}}{\delta_{c}}=0.05$ and $\frac{\delta_{2}}{\delta_{c}}=0.5$, respectively.

\section{Experimental work}

The material used for this investigation is the Aluminium-magnesium alloy Al $5083 \mathrm{H} 321$, which is widely used in shipbuilding and automotive industry. The thickness of the rolled plates as delivered by the supplier is $3 \mathrm{~mm}$. From these plates, different specimens have been manufactured, namely flat tensile specimens with a width of $8 \mathrm{~mm}$ for the determination of the stress-strain curve, and several fracture specimens with different sizes. All specimens were tested under quasi-static conditions.

Elastic properties of the material are $\mathrm{E}=68000 \mathrm{MPa}$ and $v=0.33$ and the yield stress is $\mathrm{R}_{\mathrm{p} 0.2}=243 \mathrm{MPa}$. The stress-strain curve was determined using a conventional clip gauge for the measurement of elongation. Therefore, experimental values were reported only up to maximum load, which was reached after an equivalent strain $\varepsilon_{\mathrm{eq}}=0.125$. The corresponding tensile strength is $\mathrm{R}_{\mathrm{m}}=346 \mathrm{MPa}$. An extrapolation has been added afterwards based on a 
power hardening law. It was found that anisotropy of the rolled material is minor. Therefore isotropic von Mises plasticity has been used for all calculations.

The different fracture specimens made of the Aluminium plate and used for the current investigation are summarized in Table 1. Other element sizes and types (cruciform specimens are machined as well, but are outside the scope of this investigation). All specimens are fatigue precracked.

TABLE 1: Fracture specimens

\begin{tabular}{cccc}
\hline Name & Type & size & crack length ratio a $\mathrm{W}$ \\
\hline $\mathrm{C}(\mathrm{T}) 50$ & $\mathrm{C}(\mathrm{T})$ & $\mathrm{W}=50 \mathrm{~mm}$ & 0.5 \\
\hline $\mathrm{C}(\mathrm{T}) 150$ & $\mathrm{C}(\mathrm{T})$ & $\mathrm{W}=150 \mathrm{~mm}$ & 0.5 \\
\hline $\mathrm{M}(\mathrm{T}) 100$ & $\mathrm{M}(\mathrm{T})$ & $2 \mathrm{~W}=100 \mathrm{~mm}$ & 0.3 \\
\hline $\mathrm{M}(\mathrm{T}) 300$ & $\mathrm{M}(\mathrm{T})$ & $2 \mathrm{~W}=300 \mathrm{~mm}$ & 0.2 \\
\hline
\end{tabular}

The $\mathrm{C}(\mathrm{T})$ specimens are equipped with a clip gauge for the measurement of loadline displacement, a second clip for the CTOD $\left(\delta_{5}\right)$ measurement at the crack tip and a camera (combined with a stereo microscope) to take pictures of the specimen's back surface for the determination of crack length and CTOA. The $\mathrm{M}(\mathrm{T})$ specimens use the same technique: The CTOD is measured at one crack tip only, the other crack tip is viewed by the stereo microscope. The remote displacement is measured in a distance of 1.5 times $\mathrm{W}$ for the $\mathrm{M}(\mathrm{T})$ specimens. Details of the experimental setup are described in [5].

The $\mathrm{C}(\mathrm{T})$ specimens are used for the determination of the respective material parameters, the $\mathrm{M}(\mathrm{T})$ specimens for the validation of the model with fixed material parameters. For all specimens the load-displacement curve and the $\delta_{5}$ R-curve are examined.

\section{Parameter determination}

For the current investigation, the $\mathrm{C}(\mathrm{T})$ specimens have been used to determine the respective material parameters for CTOA and the cohesive model. The $\mathrm{M}(\mathrm{T})$ specimens are used to estimate the transferability to different sizes and constraint conditions. The mesh used for the simulations is very similar for CTOA and cohesive model calculations. However, two differences exist: 1 . The boundary conditions at the ligament depend the model used, 2 . The element size at the ligament is different. For the cohesive model, the continuum elements adjacent to the cohesive interfaces have a length of $0.125 \mathrm{~mm}$, whereas the elements in the CTOA calculations are $0.25 \mathrm{~mm}$. This leads to much smaller models for the CTOA calculations and thus shorter computation times. In combination with the high robustness of the CTOA method (good convergence), the saving of computation time is a factor of about 3.

\section{CTOA simulations}

Despite numerous applications, there is still no unique definition or measuring standard for CTOA. It was proposed in [5] to determine the angle between four points closely behind the crack tip, see Fig. 1. An average value over a base length between 0.5 and $1.5 \mathrm{~mm}$ is taken for the sake of smoothness. However, for the first few millimetres of crack propagation, 
where the shear lips are formed, this method leads to unrealistically high values. The derivative of $\delta_{5}$, Eq. (1), has been used for this part.

The optical measurement as well as the CTOD-derivation show that CTOA decreases after initiation and reaches a stationary value, $\psi_{\mathrm{c}}$, after a transient phase for both $\mathrm{C}(\mathrm{T})$ specimens, see Fig. 2. Note, however, that these data may scatter significantly, the $\frac{\mathrm{d} \delta_{5}}{\mathrm{~d} \Delta a}$-curve contains averaged values. The saturation value of $5^{\circ}$, which is reached after $8 \mathrm{~mm}$ crack extension for the $\psi$-measurement, is taken as CTOA-curve for the crack propagation simulation. A numerical parameter fitting, where the experimental load-displacement and $\delta_{5} \mathrm{R}$-curves must be met, could also be employed instead to improve the coincidence between numerical and experimental results. The input for the finite element simulation is shown as the solid line in Fig. 2. The CTOA values in the simulations have a base length of $1 \mathrm{~mm}$, over which the angle is calculated by the FE program ABAQUS. The experimental (symbols) and the simulated (black solid lines) load-displacement curves and $\delta_{5}$ R-curves achieved with this parameter curve are shown in Figs 3 and 4.

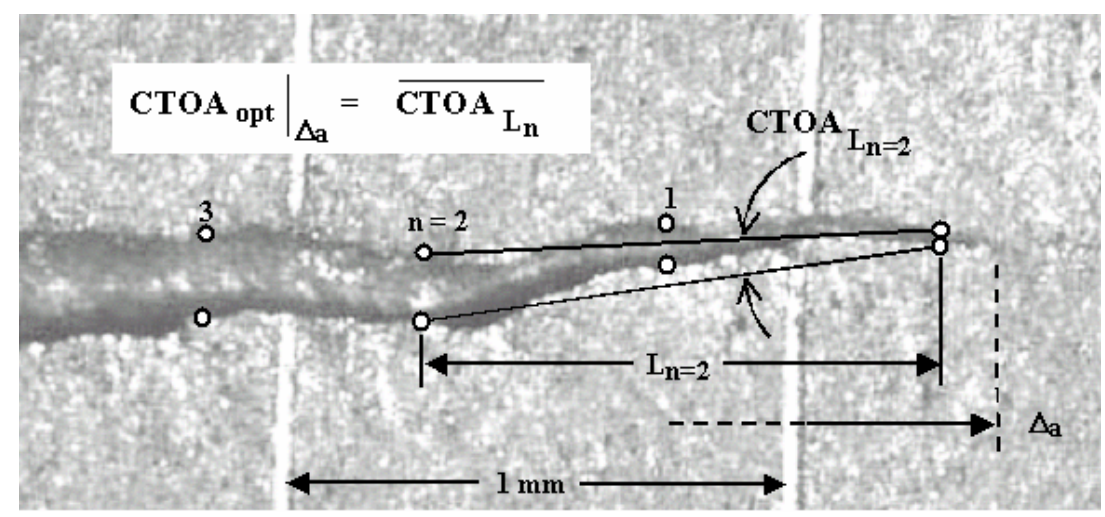

FIGURE 1. Photograph of the crack tip showing the procedure for the experimental measurement of CTOA.

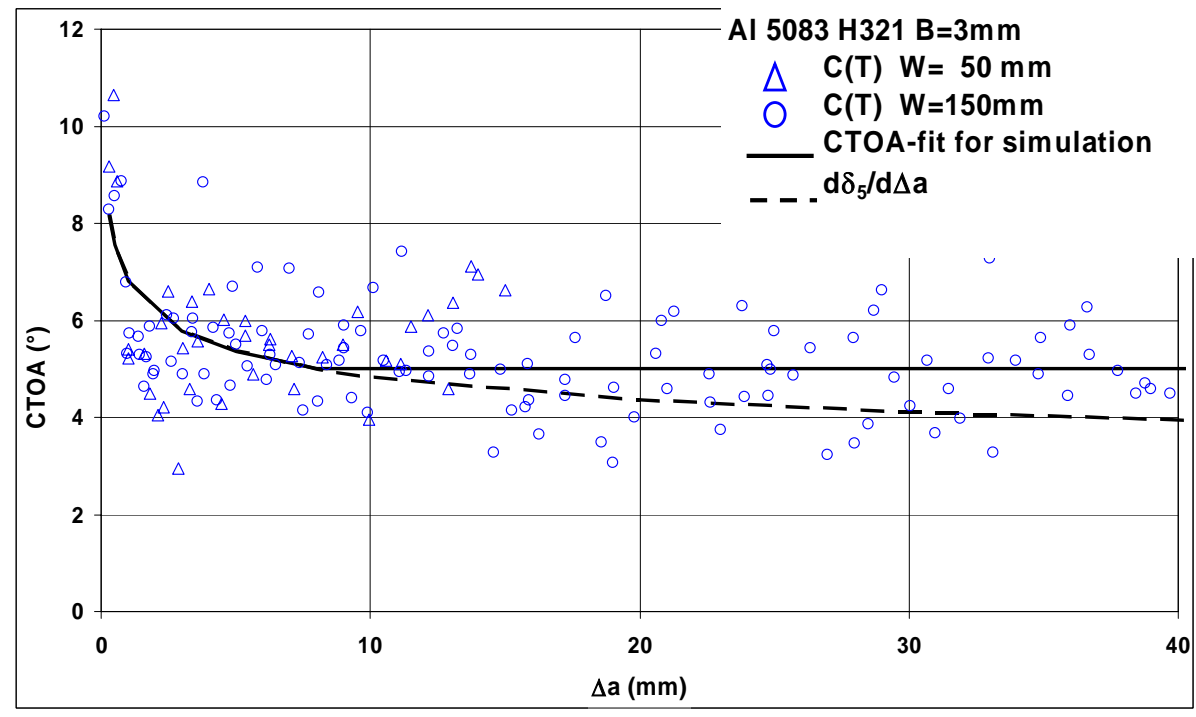

FIGURE 2. CTOA values for C(T) specimens, evaluated optically (symbols) and by derivation of the $\delta_{5}$ R-curve (dashed line), Eq. (1). With the optical method, a saturation value of $5^{\circ}$ is reached after $8 \mathrm{~mm}$ of crack extension. The curve taken as input for the numerical simulations is shown with the solid line. 

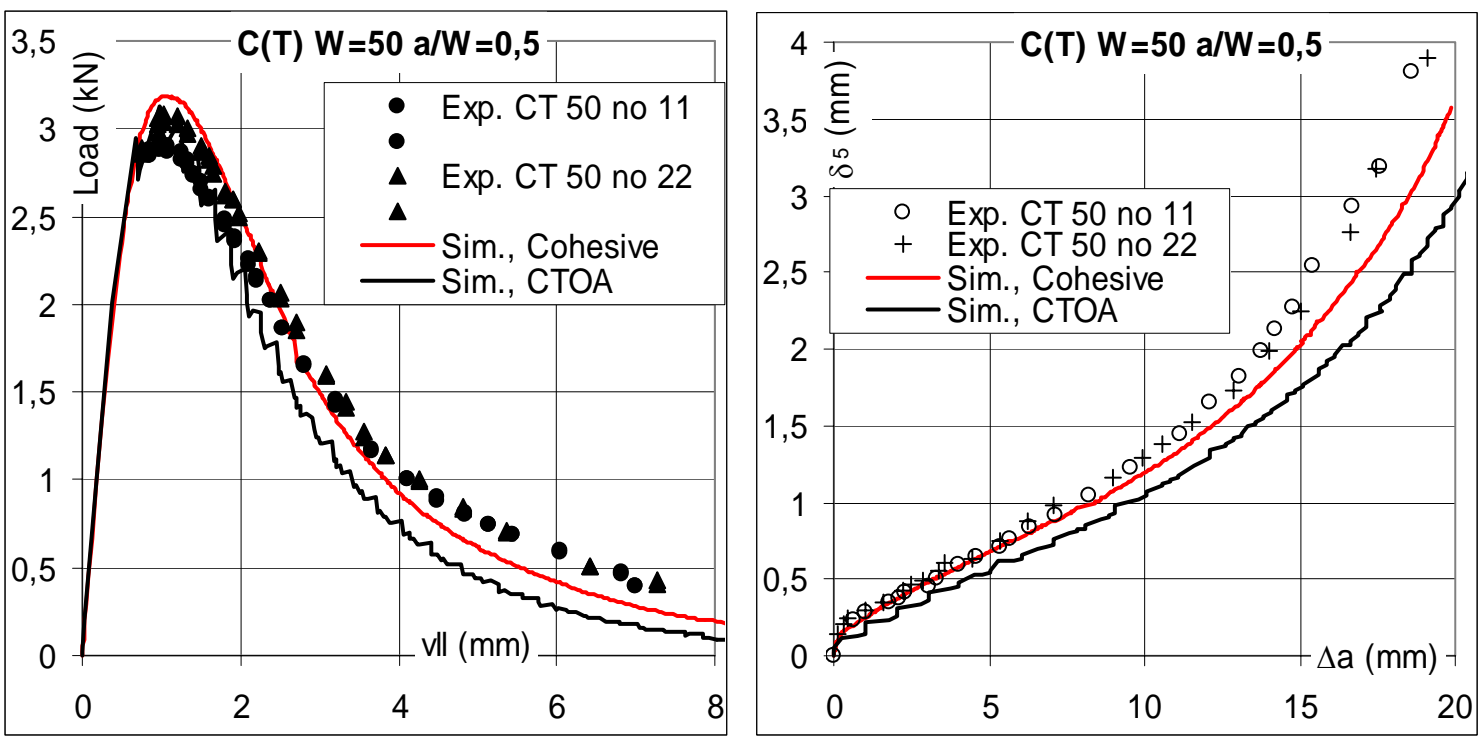

FIGURE 3: Experimental and the best fitting simulated curves (CTOA and cohesive model) for the C(T)50 specimen. Left: load-displacement curve; right: $\delta_{5}$ R-curve.
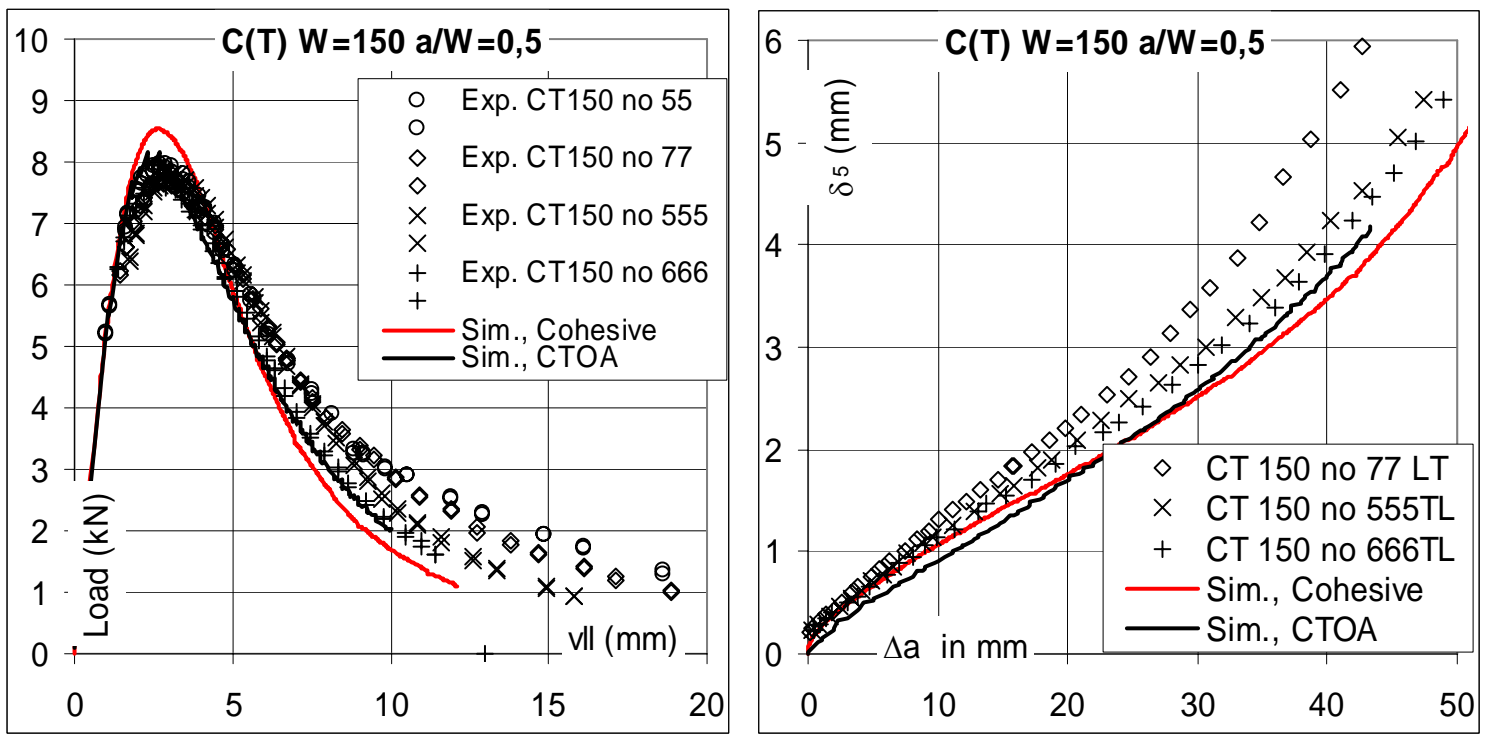

FIGURE 4: Experimental and simulated curves (CTOA and cohesive model) for the $\mathrm{C}(\mathrm{T}) 150$ specimen. Left: load-displacement curve; right: $\delta_{5} \mathrm{R}$-curve.

\section{Cohesive model simulations}

The parameters for the cohesive model must be determined using a parameter fitting. Up to now, a procedure for the determination of the cohesive model parameters of ductile materials has been developed only for normal fracture, see Cornec et al. [14]. Related to this procedure, the $J$ value at initiation, $J_{\mathrm{i}}$, is taken as a first guess for the cohesive energy, $\Gamma_{0}$, and the fracture load divided by the area of the normal projection of the inclined fracture surface yields a value, which is a lower bound of the cohesive strength, $\sigma_{0}$. Following this procedure, the cohesive energy should be in the range $\Gamma_{0}=\left[\begin{array}{ll}7 & \ldots\end{array}\right] \mathrm{kJ} / \mathrm{m}^{2}$ and the cohesive strength at 
least $\sigma_{0}=F_{\text {frac }} / A_{\text {frac }}=484 \mathrm{MPa}$. The values determined by parameter fitting - the loaddisplacement curves and the $\delta_{5}$ R-curves must meet the experimental curves for the $\mathrm{C}(\mathrm{T})$ specimens - give $\sigma_{0}=560 \mathrm{MPa}$ and $\Gamma_{0}=10 \mathrm{~kJ} / \mathrm{m}^{2}$. The resulting curves are shown in Figs 3 and 4.

\section{Validation}

The constraint difference, e.g. between $\mathrm{C}(\mathrm{T})$ and $\mathrm{M}(\mathrm{T})$ specimens, causes the so-called transferability problem, which typically results in different $\mathrm{R}$ curves for different specimens. A crack propagation model must be able to overcome these difficulties and predict $\mathrm{R}$ curves of different specimens with a single set of parameters. Therefore, two different $\mathrm{M}(\mathrm{T})$ specimens are analysed with the parameters determined in the previous section. Again, the load-deformation curve and the $\delta_{5}$ R-curve are evaluated. The results are shown in Fig. 5 for the $\mathrm{M}(\mathrm{T}) 100$ specimen and in Fig. 6 for the M(T)300 specimen. The cohesive model shows very good agreement with the experimental curves, and the CTOA simulations are fairly good for the $\mathrm{M}(\mathrm{T}) 300$ specimen, too. The reason for the deviation of the CTOA simulation from the experimental curves for the $\mathrm{M}(\mathrm{T}) 100$ specimen is probably given by the different initial region of the curve $\psi_{\mathrm{R}}(\Delta a)$, since for $\mathrm{M}(\mathrm{T})$ specimens the constant CTOA is reached after more than $10 \mathrm{~mm}$, whereas for $\mathrm{C}(\mathrm{T})$ specimen it is reached after $8 \mathrm{~mm}$, see previous section. This problem affects smaller specimens more than large specimens, as a comparison between Fig. 5 and 6 shows. Nevertheless, the maximum load, which is the most interesting quantity in industrial application, is well predicted with the CTOA model, too. In addition, the results are conservative, i.e. the real structure is more damage tolerant than the simulation predicts.
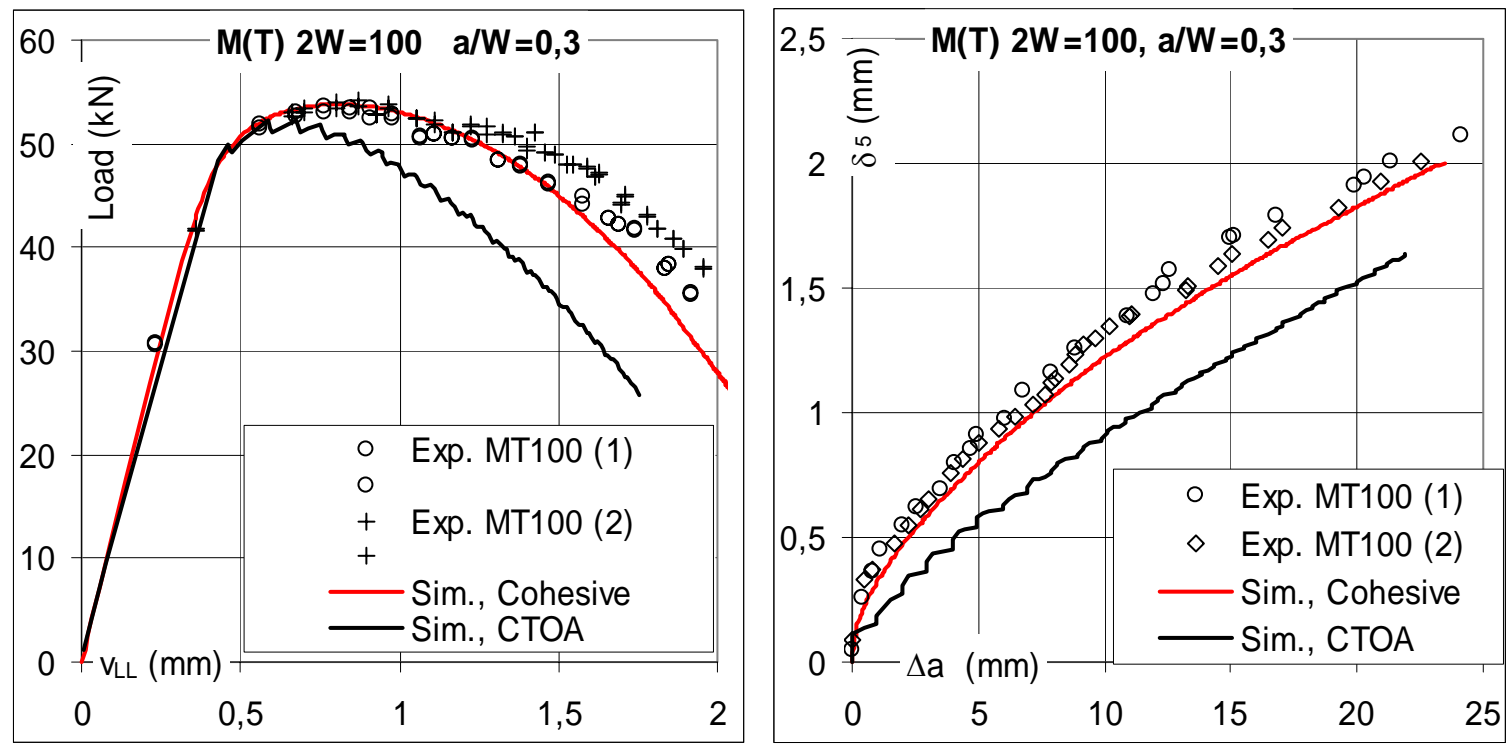

FIGURE 5: Experimental and simulated curves (CTOA and cohesive model) for the $\mathrm{M}(\mathrm{T}) 100$ specimen. Left: load-displacement curve; right: $\delta_{5}$ R-curve. 

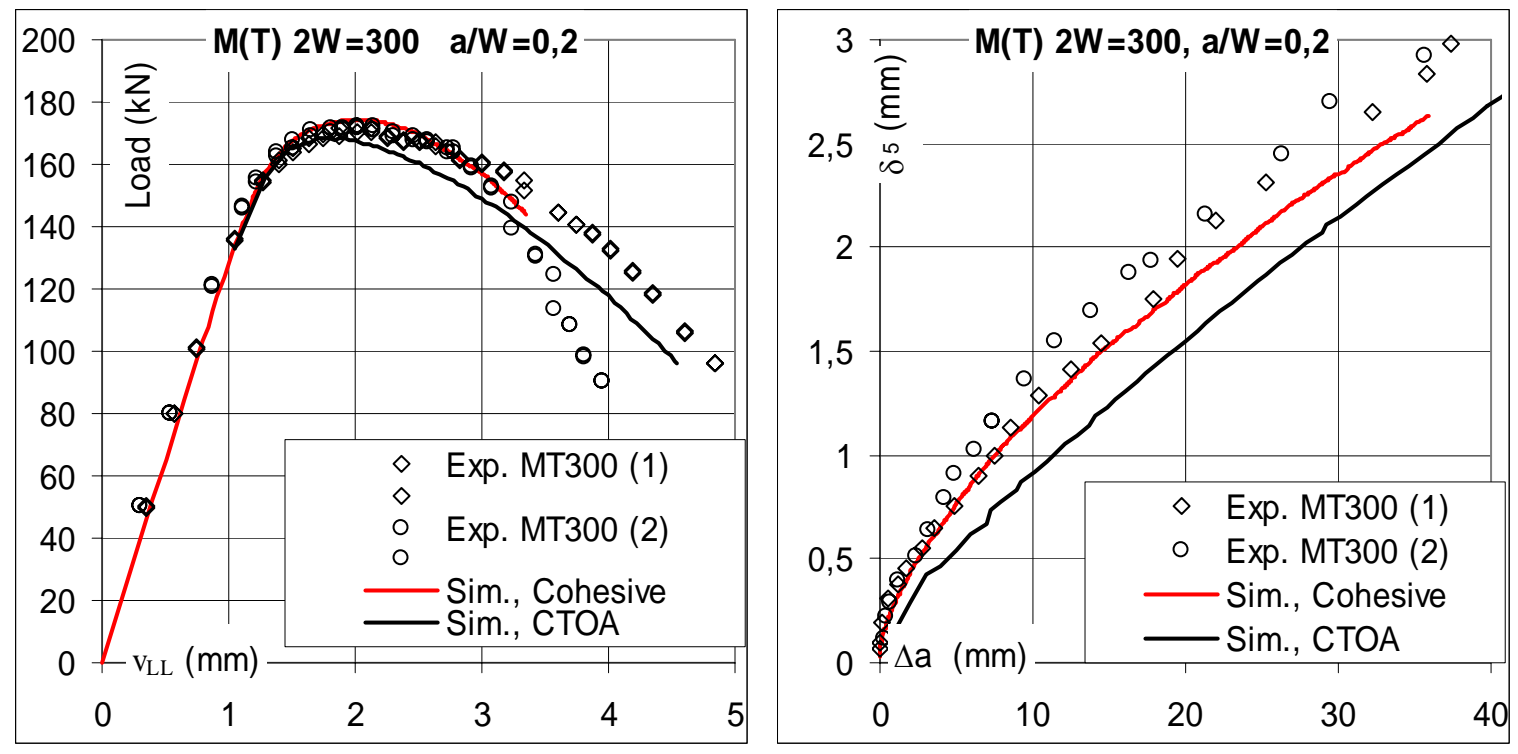

FIGURE 6: Experimental and simulated curves (CTOA and cohesive model) for the $\mathrm{M}(\mathrm{T}) 300$ specimen. Left: load-displacement curve; right: $\delta_{5} \mathrm{R}$-curve.

\section{Conclusions}

The validation of the CTOA and the cohesive model showed that a large amount of crack propagation can be predicted by these models with good accuracy. Both models are able to reproduce the experiments, and the parameters can be transferred to other constraint conditions as well. It is shown that for small specimens where the initial range of crack extension, say the first 5 to $10 \mathrm{~mm}$, is important for the overall behaviour, the variation of CTOA with crack extension, $\psi_{\mathrm{R}}(\Delta a)$, must be taken into account. For larger specimens, where this range is only a small portion of the total crack extension, the assumption of constant CTOA leads to very good results. This has been confirmed by tests with $\mathrm{C}(\mathrm{T})$ specimens up to a width of $\mathrm{W}=1000 \mathrm{~mm}$, which are not shown here.

Despite the fact, that the results for the CTOA model are not as accurate as the cohesive model, the model has some very promising advantages:

口 Method is very robust and numerically stable.

$\square \quad$ Larger elements can be used, which makes the model small and computation times short.

A single parameter curve $\psi_{\mathrm{R}}(\Delta a)$ is sufficient for different constraint conditions and sizes.

$\square \quad$ The $\psi_{\mathrm{R}}(\Delta a)$ curve can be determined with experimental methods alone.

$\square \quad$ The method is not sensitive to uncertainties in the stress-strain curve.

Advantages of the cohesive model:

The method leads to very good results for structures with different size and constraint conditions.

The two parameters of the cohesive model, $\sigma_{0}$ and $\Gamma_{0}$, are assumed to be constant and thus can easily be determined by parameter fitting. 
The cohesive model can not only be used for 2D thin walled, but also for thick or complex threedimensional structures.

$\square$ The presence of an initial crack is not essential for the cohesive model

\section{References}

1. Schwalbe, K.-H., Zerbst, U., Kim, Y.-J., Brocks, W., Cornec, A., Heerens, J. and Amstutz, H., EFAM ETM 97: The ETM Method for Assessing Crack-Like Defects in Engineering Structures, GKSS Report GKSS/98/E/6, 1998

2. Ainsworth, R. A., Bannister, A. C. and Zerbst, U., Int. J. Pres. Ves. \& Piping, vol. 77, 2001, 869-876

3. Dawicke, D. S., Sutton, M. A., Newman, J.C. Jr. and Bigelow, C. A. In Fracture Mechanics, $25^{\text {th }}$ volume, ASTM STP 1220, edited by Erdogan, F. and Hartranft, J., ASTM, Philadelphia, 1995, 358-379

4. O'Donoghue, P. E., Kanninen, M. F., Leung, C. P., Demofonti, G.. and Venzi, S.: Int. J. Pressure Vessels and Piping, vol. 70, 11-25, 1997

5. Heerens, J. and Schödel, M., Eng. Fract. Mech., vol. 70, 417-426, 2003.

6. Newman, J. C. Jr., James, M. A. and Zerbst, U.: Eng. Fract. Mech., vol. 70, 371-385, 2003

7. Schwalbe, K.-H.. In Fracture Mechanics: 26th Vol., ASTM STP 1256, 1995: 763.

8. Needleman, A., Int. J. Fracture, vol. 42, 21-40, 1990.

9. Yuan, H., Lin, G. and Cornec, A., J. Engineering Materials Technology, vol. 118, 192200, 1996.

10. Tvergaard, V. and Hutchinson, J. W., J. Mech. Phys. Solids, vol. 41, 1119-1135, 1993

11. Li, W. and Siegmund, Th., Eng. Fract. Mech., vol. 69, 2073-2093, 2003

12. Scheider, I. and Brocks, W Eng. Fract. Mech., vol. 70, 1943-1961, 2003

13. ABAQUS Version 6.4, ABAQUS Inc., Pawtucket, U.S.A., 2003

14. Cornec, A., Scheider, I. and Schwalbe, K.-H., Eng. Fract. Mech., vol. 70, 1963-1987, 2003 